\title{
A data envelopment analysis approach for assessing the efficiency of small and medium- sized wood-furniture enterprises: a case study
}

\author{
Diana P. Sari ${ }^{1}$, Naniek Utami Handayani ${ }^{1}$, M. Mujiya Ulkhaq ${ }^{1, *}$, Wiwik Budiawan ${ }^{1}$, \\ Dea Ladysia Maharani ${ }^{1}$, and Fahmi $\mathrm{Ardi}^{1}$ \\ ${ }^{1}$ Department of Industrial Engineering, Diponegoro University, 50275 Semarang, Indonesia
}

\begin{abstract}
Small and medium enterprises (SMEs) are widely recognised as the key engine of economic development. As a result of this recognition, a central issue dominating policy debates around the world and Indonesia in particular, has been how to stimulate economic growth through the development of SMEs. During and beyond the financial crisis, the SMEs in Indonesia contributed to the employment growth and gave steady decline in poverty rate. Wood-furniture industry is one of two traditional labourintensive industries in Indonesia which plays an important role in the economic development since the country is as one of the biggest furniture exporters in the world. However, the SMEs are facing difficulties in many areas, especially in spending their scarce resources efficiently. A case study to assess the efficiency of the wood-furniture SMEs has been conducted by applying the data envelopment analysis in Kangkung Village, Demak Regency, Indonesia. The results show that from ten assigned wood-furniture SMEs, there are six SMEs that are considered efficient, while the rest are regarded as inefficient. This research is expected to give some advantages to the SMEs regarding how to use their limited resources in an efficient way.
\end{abstract}

\section{Introduction}

Small and medium enterprises (SMEs) are broadly acknowledged to have a vital role in the economic development. Both developed and developing countries believe that they could bring huge economic benefits by contributing to the entrepreneurship, employment creation, as well as income generation [1-3]. Particularly in the developing countries, the SMEs are considered as important not only since they create the employment but also because they employ unskilled workers who are abundant in such countries [4].

Like other developing countries, Indonesia also has recognised the importance of the SMEs for economic development and poverty alleviation, especially during the financial crisis in 1997-1998. During that dark year, the SMEs gave big contributions to the employment growth and gave steady decline in poverty rate. Beyond the dark year, the SMEs even contributed more to economic growth compared to big enterprises due to their dependency

\footnotetext{
* Corresponding author: ulkhaq@live.undip.ac.id
} 
towards formal markets and credits [5]. In fact, the SMEs represent more than $99 \%$ of the total number of enterprises in Indonesia and employ more than $97 \%$ of the entire workforce $[6,7]$. In addition, the SME sector exported as of $16 \%$ of total non-oil exports, and accounted for $57.94 \%$ of total gross domestic product (GDP) at current prices [7].

The wood-furniture industry has an important role in the Indonesian economy, as it has great potential for both domestic and international trade. It is characterized as a labourintensive industry since it employs approximately two million people directly and eight million workers indirectly [8]. In the global market, Indonesia is one of the biggest furniture exporters in the world, along with China, Italy, Vietnam, and Malaysia. Undoubtedly, this industry is recognised as having another important role in Indonesia as a source of foreign exchange. The SMEs are the major players in the wood-furniture industry in Indonesia [9]. With this large proportion, it is no surprise about the ability of SMEs to generate more employment than larger firms.

Currently, Indonesian SMEs in the wood-furniture industry are facing an intense competition as more and more players, especially from Asian countries, enter the global market [10]. They have difficulties of handling problems in many areas, such as supply chain management, production management, accounting and financial management, human resource management, public relations, research and development, as well as decision making; among them, financial problems have a significant importance [11]. Indonesian SMEs have to be able to stay alive in the global market that has been shaped by the new economy and globalization. In addition, they have to be able to keep up in such a competitive environment that is dependent on a rigid equity structure and strong financial bodies. However; the equities of the SMEs are insufficient and the alternative resources they use in accomplishing the financial needs are limited. For this reason, the scarce resources should be used efficiently; thus, efficiency measurement is vital in terms of SMEs.

Various methods have been proposed in the measurement of efficiency, such as ratio analysis, parametric, as well as non-parametric solution methods. Among them, the nonparametric method: data envelopment analysis (DEA) proposed by [12] has been widely applied. It is a linear programming based method that is used to determine the relative efficiencies of decision making units (DMUs) when there are a lot of input and output. It is also could be applied when the outputs have different measurement units $[13,14]$. In addition, DEA does not make any possible assumptions related to the structure of the production function [15]. These flexibilities make DEA is preferable to other methods (see [16-18] for the examples of the applications of the DEA in the various fields).

This research tried to apply DEA to assess the efficiency of wood-furniture SMEs in Kangkung Village, which is located in Demak Regency, Central Java Province, Indonesia. The wood-furniture industry is one of the most strategic industries in developing the economy of Demak Regency. However, according to the preliminary study, there are a lot of inefficiencies that have been found there, such as inefficiency in the use of raw materials and supporting materials, i.e., woods, paints, nails, and glue; and the workers that are frequently in an idle condition during working hours. This condition causes the price of the products are more expensive than similar products that are manufactured outside the regency. As a consequence, the SMEs are found to gain losses; in average, there are losses of IDR 500,000 to 3,000,000 per month. The efficiency of factors of production is considered very crucial to make the SMEs obtain the maximum profit by spending production cost as minimum as possible. It is expected that this study shall provide benefits for the SMEs to determine at what ratio they use their resources efficiently and to determine the convenient resource amount to be able to achieve the existent outputs. 


\section{Research design}

DEA which was applied in this research is a linear programming-based technique for measuring the relative performance of organizational units (they are regarded as DMUs) where the presence of multiple inputs and outputs makes comparisons difficult. It makes no assumptions regarding the distribution of inefficiencies or the functional form of the production function (although it imposes some technical restrictions such as monotonicity and convexity [19]). Instead, it uses the input and output data themselves to compute, using linear programming methods, the production possibility frontier.

There are two basic approaches in the DEA, i.e., constant returns to scale (CRS) approach and variable returns to scale (VRS). The first which is also well-known as CCR model is considered as the simplest form of DEA since there is no assumption that any positive or negative economies of scale exist. It is assumed is that a small unit should be able to operate as efficiently as a large one. The second one that is also called as BCC model is closely related to the standard CRS approach as is evident in the dual of the VRS approach. The difference compared to the CRS approach is the introduction of the convexity condition. This additional constraint gives the frontiers piecewise linear and concave characteristics, see [20] for the detail of the BCC model. This research employed the first approach since it is assumed that the ratio of input and output addition is equal.

The data used in this study represent a cross-section of wood-furniture SMEs in Kangkung Village which have differing ownership, financing, and operational characteristics. Ten variables were selected as inputs while the only one output is the amount of wood-furniture produced in units $(y)$. Those ten inputs are classified into two variables, i.e., labour and costs. The labour may be expressed as the number of labour employed $\left(x_{1}\right)$ and labour costs in thousands of IDR $\left(x_{2}\right)$. The associated costs (all are in thousands of IDR) are among key factors considered in all studies but their exact definition varies among different studies. The costs may be aggregated into overhead cost $\left(x_{3}\right)$, raw materials cost $\left(x_{4}\right)$, and supporting materials cost: nails $\left(x_{5}\right)$, glues $\left(x_{6}\right)$, sandpapers $\left(x_{7}\right)$, and paints $\left(x_{8}\right)$. Since secondary data are not available, we conducted field observation to obtain primary data which are used to accomplish the goal of the research.

Each $j$ th DMU $(j=1,2, \ldots, n)$ is considered to be a production unit that uses $i$ inputs $x_{i j}$ $(i=1,2, \ldots, m)$ to produce an output $y_{j}$ (note that there is only one output considered in this study). For a particular DMU $j, h_{j}$ is its efficiency; $x_{i j}$ and $y_{j}$ are its inputs and output; and $v_{j}$ and $u_{i j}$ are the calculated weights for the output and $i$ th input. The model can be written in a linear programming problem (LPP) as follows:

$$
\begin{array}{ll}
\text { Maximize } & :{ }^{h_{j}}=v_{j} y_{j} \\
& \sum_{i=1}^{m} u_{i} x_{i j}=1 \\
& v_{j} y_{j}-\sum_{i=1}^{m} u_{i} x_{i j} \leq 0 \\
& v_{j} \geq 0 ; u_{i} \geq 0 .
\end{array}
$$

The LPP is solved for each DMU; thus, if there are $n$ DMUs, $n$ LPPs must be solved. Besides the efficiency index, the DEA models yield the variables weights, benchmarks, and targets for the inefficient DMUs. The last two are determined from the values of the dual variables, i.e., by solving the dual LPPs or by the use of the complementary slack theorem. 


\section{Case study: Results and discussion}

DEA was applied in this study for demonstrating how to assess the efficiency of woodfurniture SMEs in Kangkung Village, Demak Regency. As stated in Section 1, the SMEs in this area have inefficiency issues. We then assigned ten wood-furniture SMEs in which each is regarded as DMU. Profile of the SMEs is shown in Table 1.

Table 1. Profile of the assigned SMEs.

\begin{tabular}{|c|l|c|}
\hline DMU & Name of the owner & \multicolumn{1}{c|}{ Address } \\
\hline$j=1$ & Nindam & RT 04 RW 02, Kangkung Village \\
\hline 2 & Nasri & RT 07 RW 02, Kangkung Village \\
\hline 3 & Dulkaris & RT 04 RW 02, Kangkung Village \\
\hline 4 & Sumardi & RT 03 RW 02, Kangkung Village \\
\hline 5 & Jisum & RT 04 RW 02, Kangkung Village \\
\hline 6 & Nursaid & RT 05 RW 01, Kangkung Village \\
\hline 7 & Pur & RT 03 RW 01, Kangkung Village \\
\hline 8 & Mardi & RT 03 RW 01, Kangkung Village \\
\hline 9 & Jariyah & RT 05 RW 02, Kangkung Village \\
\hline $10=n$ & Kasmani & RT 06 RW 01, Kangkung Village \\
\hline
\end{tabular}

To assess the efficiency of each DMU using the DEA, the LPP that has been expressed in Section 2 has to be solved. It needs inputs and output as coefficients for the decision variables. Table 2 shows the particular inputs as well as output for the assigned SMEs. Note that the second column is measured in the number of products unit, the second column is in person unit, while for the fourth column to the tenth column are in thousands of IDR. To be easier, in this study, the output of each DMU is presented in an equal unit, i.e., 40 units. It means that, for instance, for DMU 1, to produce 40 units of the wooden furniture, it needs 3 employees; IDR 1.35 million to give salaries for those three employees; IDR 550 thousand as overhead cost; IDR 3 million as raw materials cost; and a total of IDR 1.36 million as supporting materials cost.

Table 2. Inputs and output of the assigned SMEs.

\begin{tabular}{|c|c|c|c|c|c|c|c|c|c|}
\hline DMU & $\boldsymbol{y}_{i}$ & $\boldsymbol{x}_{1 j}$ & $\boldsymbol{x}_{2 j}$ & $\boldsymbol{x}_{3 j}$ & $\boldsymbol{x}_{4 j}$ & $\boldsymbol{x}_{5 j}$ & $\boldsymbol{x}_{6 j}$ & $\boldsymbol{x}_{7 j}$ & $\boldsymbol{x}_{8 j}$ \\
\hline 1 & 40 & 3 & 1,350 & 550 & 3,000 & 40 & 120 & 450 & 750 \\
\hline 2 & 40 & 3 & 1,500 & 550 & $4,312.50$ & 33 & 166.5 & 400 & 825 \\
\hline 3 & 40 & 4 & 1,800 & 550 & 3,450 & 33 & 102.5 & 370 & 800 \\
\hline 4 & 40 & 3 & 1,170 & 600 & 3,500 & 38 & 148 & 400 & 650 \\
\hline 5 & 40 & 4 & 2,040 & 700 & 4,200 & 40 & 150 & 450 & 850 \\
\hline 6 & 40 & 5 & 2,350 & 650 & 3,150 & 30 & 120 & 500 & 700 \\
\hline 7 & 40 & 5 & 2,800 & 700 & 3,300 & 44 & 123 & 500 & 725 \\
\hline 8 & 40 & 4 & 2,600 & 700 & $3,967.50$ & 38 & 148 & 500 & 670 \\
\hline 9 & 40 & 4 & 2,080 & 750 & $3,622.50$ & 44 & 129 & 400 & 800 \\
\hline 10 & 40 & 4 & 1,800 & 550 & 3,600 & 33 & 164 & 370 & 725 \\
\hline
\end{tabular}

This research employed sistema integrado de apoio a decisão (SIAD) software [21], a Portuguese version of integrated system for decision support (ISYDS) to solve those LPPs. The software is capable of dealing with 150 DMUs, 20 variables (inputs or outputs), and works with a six decimals accuracy. Although for other research areas 150 units might be insufficient, this number is able to deal with the problem in this study. A comparison between SIAD and other software packages to solve the DEA could be found in [22].

The weights of inputs and output of the assigned SMEs are presented in Table 3. Note that the weights differ depending on the quantity of the variables used in each assigned SME. In DMU 1 and 6, there are two variables that affect the efficiency, i.e., the output and raw materials cost as a sole input with the weights of 0.025 and 0.00000033 (DMU 1) and 0.025 and 0.00000019 (DMU 6) for the output and the input respectively. It seems that in DMU 1 
and DMU 6, they already used their budget allocation to be spent on raw materials cost efficiently as there are seldom seen a waste of woods in the process of making wooden furniture. However, in DMU 5, the SME is regarded to be inefficient as the weight for the output is 0.0218 and the weights of five significant inputs are $0.00008297,0.00001180$, $0.00000068,0.00001180$, and 0.00000027 for the number of employees, cost of nails used, cost of glues used, cost of sandpaper used, and cost of paints used respectively.

Table 3. Weights of inputs and output of the assigned SMEs $\left(\times 10^{-6}\right)$.

\begin{tabular}{|c|c|c|c|c|c|c|c|c|c|}
\hline DMU & $\boldsymbol{y}_{j}$ & $\boldsymbol{x}_{1 j}$ & $\boldsymbol{x}_{2 j}$ & $\boldsymbol{x}_{3 j}$ & $\boldsymbol{x}_{4 j}$ & $\boldsymbol{x}_{5 j}$ & $\boldsymbol{x}_{6 j}$ & $\boldsymbol{x}_{7 j}$ & $\boldsymbol{x}_{8 j}$ \\
\hline 1 & $25,000.00$ & 0 & 0 & 0 & 0.33 & 0 & 0 & 0 & 0 \\
\hline 2 & $25,000.00$ & 0 & 0.16 & 1.04 & 0 & 0 & 0 & 0.47 & 0 \\
\hline 3 & $25,000.00$ & 0 & 0 & 0 & 0.18 & 0 & 0 & 1.02 & 0 \\
\hline 4 & $25,000.00$ & 0 & 0 & 0 & 0 & 5.42 & 1.47 & 0.60 & 0 \\
\hline 5 & $21,796.27$ & 82.97 & 0 & 0 & 0 & 11.80 & 0.68 & 11.80 & 0.27 \\
\hline 6 & $25,000.00$ & 0 & 0 & 0 & 0.19 & 0 & 0 & 0 & 0 \\
\hline 7 & $24,332.40$ & 0 & 0 & 0 & 0 & 0 & 2.39 & 0.28 & 0.78 \\
\hline 8 & $24,464.83$ & 0 & 0 & 0 & 0 & 0 & 1.91 & 0 & 1.07 \\
\hline 9 & $23,778.29$ & 0 & 0 & 0 & 0.13 & 0 & 0 & 0.87 & 0.22 \\
\hline 10 & $25,000.00$ & 0 & 0 & 0.86 & 0 & 3.81 & 0 & 0 & 0.36 \\
\hline
\end{tabular}

Labels for efficient and inefficient SMEs are represented as technical efficiency that is shown in Table 4 . The efficiency values range from 0 to 1 , whereas the more efficient SME has a value that approaches one. Note that the value is a relative efficiency which is the result of normalizing the efficiency value of a DMU with another DMU which has "the best" performance, or "the most" efficient one. Table 4 shows that there are 4 inefficient SMEs, i.e., DMU 5, DMU 7, DMU 8, and DMU 9 as the technical efficiencies for those SMEs are less than one. Those SMEs could improve their efficiencies by benchmarking against more efficient SMEs. The benchmark SMEs are presented in Table 4 as well. For example, the efficient DMU 3 could serve as a benchmark for the inefficient DMU 5 and DMU 9; and DMU 7 could mimic DMU 6 to improve its technical efficiency.

Table 4. Technical efficiency and benchmark of each DMU.

\begin{tabular}{|c|c|c|c|}
\hline DMU & Technical Efficiency & Benchmark & Remark \\
\hline 1 & 1.00 & - & Efficient \\
\hline 2 & 1.00 & - & Efficient \\
\hline 3 & 1.00 & - & Efficient \\
\hline 4 & 1.00 & - & Efficient \\
\hline 5 & 0.87 & DMU 3 & Inefficient \\
\hline 6 & 1.00 & - & Efficient \\
\hline 7 & 0.97 & DMU 6 & Inefficient \\
\hline 8 & 0.97 & DMU 4 & Inefficient \\
\hline 9 & 0.95 & DMU 3 & Inefficient \\
\hline 10 & 1.00 & - & Efficient \\
\hline
\end{tabular}

\section{Conclusion}

The DEA has been presented in this paper to show how to calculate the relative efficiency of the SMEs (regarded as DMUs). A case study was conducted in Kangkung Village since the wood-furniture SMEs there have faced difficulties in spending their limited resources to produce the intended outputs, i.e., the inefficiency issues. There are ten assigned woodfurniture SMEs to be assessed. The results are depicted in Table 3 and Table 4 that are shown the weights of inputs and output as well as the technical efficiencies. Note that we used one variable as the output and ten variables as the inputs (see Section 2 for the detail). 
There are six SMEs that are considered as efficient DMUs, i.e., DMU 1, DMU 2, DMU 3, DMU 4, DMU 6, and DMU 10 and the rest are regarded as inefficient (see Table 4). Those four inefficient SMEs, they could improve their efficiencies by making some improvements in the influential variables. The improvements could be made by adjusting the input variables. Decreasing in input variables can be relieved by increasing labour productivity, spending woods consumption wisely, careful use of nails and glues, minimizing electricity consumption, saving the use of sandpapers by reusing them, and using the paints sufficiently by using a good quality brand which has an economical price.

\section{References}

1. Z.J. Acs, S. Desai, J. Hessels, Small Bus. Econ. 31, 3 (2008)

2. J.W. Kang, A. Heshmati, Small Bus. Econ. 31, 4 (2008)

3. M. Ayyagari, A. Demirguc-Kunt, V. Maksimovic, Policy Research Working Paper No. 5631 (The World Bank, Washington, D.C., 2011)

4. C. Philips, S. Bhatia-Panthaki, J. Int. Dev. 9 (2007)

5. A. Berry, E. Rodriguez, H. Sandee, B. Indones. Econ. Stud. 37, 3 (2001)

6. A. Mourougane, OECD Economics Department Working Papers No. 995 (OECD Publishing, Paris, 2012)

7. Kementerian Koperasi \& Usaha Kecil dan Menengah Republik Indonesia (Kemenkop dan UKM), Perkembangan Data Usaha Mikro, Kecil, Menengah (UMKM) dan Usaha Besar (UB) Tahun 2011-2012 (Kemenkop \& UKM, Jakarta, 2012)

8. Kementerian Perdagangan Republik Indonseia, Indonesian Furniture: Creativity in Wood (Kementerian Perdagangan, Jakarta, 2008)

9. A.P. Sugarda, T.T. Tambunan, Furniture Industry in Indonesia: The Labour Market and Gender Impact of the Global Economic Slowdown on Value Chains (Federal Ministry for Economic Cooperation and Development, Jakarta, 2009)

10. J. Ratnasingam, F. Ioras, Holz als Roh- und Werkstof 61, 3 (2003)

11. A. Büyükkeklik, H. Dumlu, S. Evci, Int. J. Econ. Financ. 8, 6 (2016)

12. A. Charnes, W.W. Cooper, E. Rhodes, Eur. J. Oper. Res. 2, 6 (1978)

13. R. Allen, E. Thanassoulis, Eur. J. Oper. Res. 154, 2 (2004)

14. R. Ramathan, An Introduction to Data Envelopment Analysis: A Tool for Performance Measurement (Sage Publications, New Delhi, 2003)

15. C. Reverte, I. Guzman, Appl. Econ. 42, 21 (2010)

16. A Nabavi-Pelesaraei, R. Abdi, S. Rafiee, H.G. Mobtaker, J. Clean. Prod. 65 (2014)

17. K.B. Atici, V.V. Podinovski, Omega 54 (2015)

18. L. Chen, G. Jia, J. Clean. Prod. 142, 2 (2017)

19. R. Färe, S. Grosskopf, C.A.K. Lovell, Production Frontiers (Cambridge University Press, Cambridge, 1994)

20. R.D. Banker, A. Charnes, W.W., Cooper, Manage. Scie. 30, 9 (1984)

21. L.A. Meza, L.B. Neto, J.C.C.B.S. de Mello, E.G. Gomes, Pesqui. Oper. 25, 3 (2005) 